\title{
Malignant intracerebral giant nerve sheath tumor in a 14-month-old girl with neurofibromatosis type 1
}

\author{
Namik Öztanır
}

Received: 12 December 2008 / Published online: 7 March 2009

(C) Springer-Verlag 2009

\section{Dear Editor:}

We appreciate the interest shown to our article 'Malignant intracerebral giant nerve sheath tumor in a 14-month-old girl with neurofibromatosis Type 1: a case report' [1] by Dr. Nabavizadeh. We are also thankful for the further information he provided, like the features of MINST in MR spectroscopy. In our analysis of the literature, we noticed that only two adult cases out of a total number of eight cases (including the presented case) had supratentorial tumors. The review of Dr. Nabavizadeh adds three more adult cases with supratentorial tumors (the article of De Cauwer et al. was published during the review process of our paper, unfortunately, we missed the chance of citing this interesting article), changing our hypothesis regarding the age and location. Triton variant of MINST is rare and the association of NF-1 and triton variant of MINST may be more common than the association of MINST and NF-1, but the rarity of these cases limits a more rational and reliable analysis.

\section{Reference}

1. Oztanir N, Emmez H, Aytar MH, Dogan M, Kaymaz M, Baykaner MK (2009) Malignant intracerebral giant nerve sheath tumor in a 14-month-old girl with neurofibromatosis type 1: a case report. Childs Nerv Syst 25:253-256

N. Öztanır $(\bowtie)$

Gazi Universitesi Hastanesi Beyin ve Sinir

Cerrahisi Polikliniði1. Kat,

06500 Ankara, Turkey

e-mail: mhaytar@yahoo.com 